\title{
(2) OPEN ACCESS \\ Feasibility and effectiveness of tools that support communication and decision making in life-prolonging treatments for patients in hospital: systematic review
}

\author{
Maureen Thodé (D) , ${ }^{1} \mathrm{H}$ Roeline W Pasman (D) , 1,2 \\ Liesbeth M van Vliet (D) , ${ }^{3}$ Olga C Damman (D) , ${ }^{1}$ Johannes C F Ket, ${ }^{4}$ \\ Anneke L Francke (D) , ${ }^{1,5}$ Irene $\mathrm{P}$ Jongerden (D) ${ }^{1}$
}

\begin{abstract}
- Additional material is published online only. To view, please visit the journal online (http://dx.doi.org/10.1136/ bmjspcare-2020-002284)
\end{abstract}

For numbered affiliations see end of article.

\section{Correspondence to} Dr Irene P Jongerden, Department of Public and Occupational Health, Amsterdam UMC - Locatie VUMC MF D251, 1081 BT Amsterdam, The Netherlands:

i.jongerden@amsterdamumc.nl

Received 27 February 2020 Revised 12 August 2020 Accepted 4 September 2020

\section{A Check for updates}

(c) Author(s) (or their employer(s)) 2020. Re-use permitted under CC BY-NC. No commercial re-use. See rights and permissions. Published by BMJ.

\footnotetext{
To cite: Thodé $M$, Pasman HRW, van Vliet LM, et al. BMJ Supportive \& Palliative Care Epub ahead of print: [please include Day Month Year]. doi:10.1136/ bmjspcare-2020-002284
}

\section{ABSTRACT \\ Objective Patients with advanced diseases and frail older adults often face decisions regarding life-prolonging treatment. Our aim was to provide an overview of the feasibility and effectiveness of tools that support communication between healthcare professionals and patients regarding decisions on life-prolonging treatments in hospital settings.}

Design Systematic review: We searched PubMed, CINAHL, PsycINFO, Embase, Cochrane Library and Google Scholar (2009-2019) to identify studies that reported feasibility or effectiveness of tools that support communication about life-prolonging treatments in adult patients with advanced diseases or frail older adults in hospital settings. The Mixed Methods Appraisal Tool was used for quality appraisal of the included studies.

Results Seven studies were included, all involving patients with advanced cancer. The overall methodological quality of the included studies was moderate to high. Five studies described question prompt lists (QPLs), either as a stand-alone tool or as part of a multifaceted programme; two studies described decision aids (DAs). All QPLs and one DA were considered feasible by both patients with advanced cancer and healthcare professionals. Two studies reported on the effectiveness of QPL use, revealing a decrease in patient anxiety and an increase in cues for discussing end-of-life care with physicians. The effectiveness of one DA was reported; it led to more understanding of the treatment in patients.

Conclusions Use of QPLs or DAs, as a single intervention or part of a programme, may help in communicating about treatment options with patients, which is an important precondition for making informed decisions.

\section{BACKGROUND}

Patients with advanced disease and older frail adults often face difficult decisions regarding life-prolonging treatment in hospital settings, such as starting, continuing or stopping palliative chemotherapy, antibiotics, artificial feeding and hydration. ${ }^{12}$ These treatments have no curative intent and may have limited benefit besides prolongation of life or symptom management. Furthermore, they may have harmful side effects and lead to a reduction in the quality of life. ${ }^{3-5}$

Decisions on starting or stopping lifeprolonging treatment are often preference sensitive. ${ }^{67}$ There is often no evidence for the superiority of one option over another and the best choice depends on how the individual values the risks and benefits of different options. ${ }^{89}$

Ideally, decisions regarding lifeprolonging treatment are made by reaching agreement between the patient (and family), nurses and physicians, following discussion of the treatment options. ${ }^{10}$ The process of shared decision making can support these discussions by helping both patients and healthcare professionals to explicitly consider the patient's value trade-off in light of the existing treatment options, including the option of taking no action, and incorporate this trade-off in a final decision. ${ }^{611} 12$ The role of healthcare professionals in shared decision making is to convey, prioritise and structure all the 
relevant information relating to the different treatment options and elicit and discuss the patient's values and preferences. ${ }^{1113}$

Currently, decisions about life-prolonging treatment are often made in a dialogue between the patient and the physician, with nurses sometimes having a supporting role. ${ }^{1415}$ Physicians often avoid discussing the option of stopping or forgoing life-prolonging treatment and can be uncertain about how to discuss end-of-life topics and patients' incurable status. ${ }^{16-18}$ This in turn can lead to inappropriate treatment decisions, such as continuing aggressive treatment in patients whose personal values and needs are overlooked. ${ }^{19} 20$

In order to facilitate communication and decision making, a multitude of tools have been developed, such as option grids, decision aids (DAs) and question prompt lists (QPLs). These tools have been developed and tested mainly for medical (curative) treatment decisions and screening. ${ }^{21-23}$ Several tools have been developed to support decision making in endof-life issues; ${ }^{24-26}$ however, they are often focused on (advance) care planning ${ }^{27}$ or on decision making in hypothetical situations instead of actual decisions about treatments that have no curative intent, though they may affect quality of life. ${ }^{29}$ Due to advances in technology and an increase in the number of frail older adults, we expect an increasing challenge in finding a balance between clinical imperatives to treat and aligning decisions with the person's preferences in the context of their life-limiting condition. Therefore, the objective of our review was to provide an overview of the feasibility and effectiveness of tools that support healthcare professionals and patient (and family) communication regarding decisions on life-prolonging treatments in hospital settings based on a broad range of study designs. Our research questions were: (1) What evidence exists on the feasibility of tools that support the communication regarding life-prolonging treatment options between patients, family members and healthcare professionals in hospital inpatient and outpatient clinics? (2) What evidence exists on the effectiveness of these tools?

\section{METHODS}

\section{Design}

A systematic review of the literature was conducted to identify studies that examined tools that support communication between patients, family and healthcare professionals about life-prolonging treatments and/or quality-of-life decision for hospitalised patients. This systematic review was conducted and reported in line with the Preferred Reporting Items for Systematic Reviews (PRISMA) statement ${ }^{30}$ (online supplemental material 1) and registered in PROSPERO (CRD42019120908), available at https://www. crd.york.ac.uk/prospero/display_record.php? ID = CRD42019120908.

\section{Search strategy}

PubMed, CINAHL, PsycINFO, Embase and the Cochrane Library were systematically searched for the period up to 11 December 2018 (PubMed, CINAHL and PsycINFO) and 10 January 2019 (Embase and the Cochrane Library). We also searched for additional references in Google Scholar on 11 January 2019. The full search strategies are provided in online supplemental material 2. In addition, we consulted 16 international experts in shared decision making or end-of-life care to ask for any additional tools and we checked the reference lists in the included studies.

\section{Eligibility criteria}

We selected studies published between January 2009 and January 2019. This time frame was chosen in agreement with experts and in line with previous reviews, ${ }^{24} 25$ because we wanted to find tools that are still relevant and are used in common clinical practice. This included tools that were developed before 2009 but are still being used in later studies. Original studies were eligible for inclusion if they focused on tools that support treatment decisions in hospital inpatient or outpatient settings in adults (aged 18 or older) in the last phase of life, in other words have an advanced incurable disease or are frail and elderly; on communication about decisions on life-prolonging treatment between patients and healthcare professionals (at least) and on outcomes regarding the feasibility (adoption, usage or satisfaction with use) of the tool or outcomes regarding the effects on patients, family and/or healthcare professionals.

Studies were excluded if the tool focused on populations with dementia or other cognitive problems, due to the barriers in communication and reduced decisional capacity, which influences the dialogue ${ }^{31}$ or did not focus on actual treatment decisions, but only on future possible situations, such as regarding cardiopulmonary resuscitation.

We did not apply restrictions beforehand regarding the publication language.

\section{Study selection}

Duplicates were removed using EndNote X8 (by MT). Subsequently, in Endnote, we restricted the time frame to 10 years. Titles and abstracts were screened to determine whether studies were potentially eligible by two researchers (MT and IJ), with the aid of the programme Rayyan (Qatar Computing Research Institute). ${ }^{32}$ In the next selection step, the full texts were screened by two researchers (MT and IJ) to determine if studies fulfilled the eligibility criteria. Differences in opinions about inclusion were resolved through discussion with two other researchers (HP and AF). The study selection procedure and results can be found in the flowchart in figure 1. 


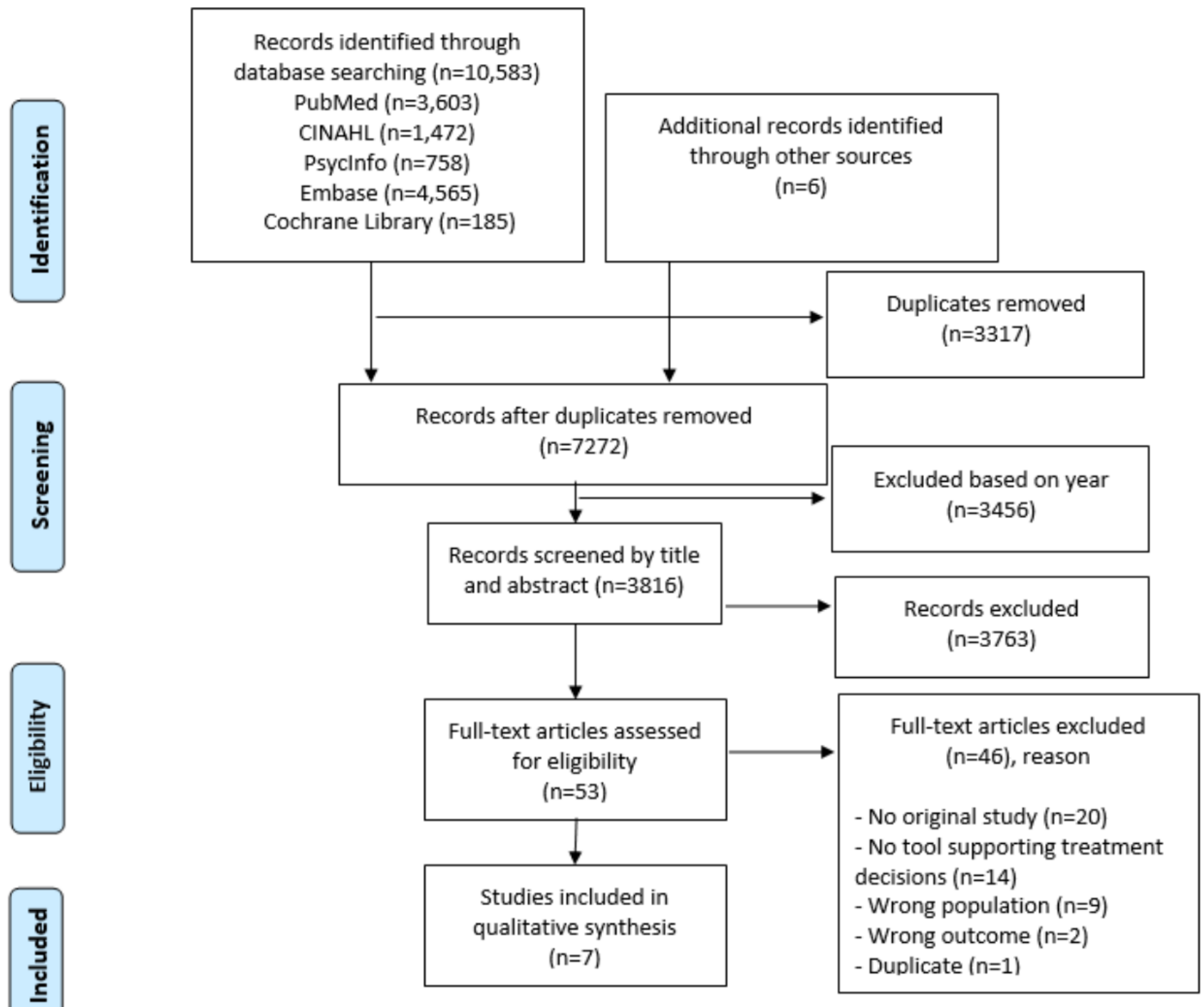

Figure 1 Flowchart.

\section{Data selection}

Two researchers (MT and IJ) independently extracted the data from the included studies using a predefined form. Disagreements were resolved through discussion. The following study characteristics were extracted: country, study design, study aims, setting (inpatient or outpatient), study population, number of participating patients and/or healthcare professionals and the age (mean or median) of the participants.

On feasibility, we extracted data on the evaluation of the content and usage. For effectiveness, we extracted data on outcomes measured in patients, family or healthcare professionals, related to use of the tool.

\section{Quality assessment}

Studies that met the inclusion criteria were independently evaluated by two researchers (MT and IJ) for methodological quality using the Mixed Methods Appraisal Tool (MMAT), V.2018. ${ }^{33}$ This tool has been proven to be effective for systematically assessing the quality of studies with quantitative designs (randomised controlled trials, non-randomised trials and quantitative descriptive studies) or qualitative designs and mixed methods studies. Each study was assessed within its methodological domain and scored on five core quality items. The presentation of overall scores from the ratings is not generally recommended, since information on problematic aspects is lost. ${ }^{33}$ However, for clarity and interpretation, we decided to report the MMAT scores for the included articles, ranging from $0 \%$ (none of the criteria are met) to $100 \%$ (all criteria are met). Again, in the case of discrepancies in the quality assessment, the researchers (MT and IJ) reached consensus through discussion.

\section{Data synthesis}

Data on feasibility and effectiveness were tabulated. We decided a priori not to do a meta-analysis because of expected heterogeneity in study design and in outcomes measured. Instead, we provide a narrative 
summary, by conducting a qualitative synthesis to identify key themes.

\section{RESULTS}

The search retrieved 10589 references. After removing duplicates and imposing a date restriction, we identified 3816 references in total for screening the title and abstract for eligibility (figure 1). Most of these references (3762) were excluded during screening, mainly because they did not include a tool supporting treatment decisions or because they did not focus on adult patients in the last phase of life without dementia or other cognitive impairments. After reading the full texts of the remaining 53 references, 7 studies ${ }^{18} 35-40$ met the criteria of our review.

The included studies were all conducted in adults with advanced cancer in outpatient hospital settings. The publication dates of these studies ranged from 2010 to 2019. The studies took place in Australia, ${ }^{35} 36$ the USA ${ }^{38} 40$ the Netherlands, ${ }^{39}$ both Australia and Canada $^{18}$ and both Australia and the USA. ${ }^{37}$ In total, 520 patients (min 27, max 207), 105 relatives (min 11, $\max 80$ ) and 42 healthcare professionals (min 6, max 13) were included in the studies. Median age of included patients varied from 55 to 72 years. Table 1 shows the main characteristics of the seven included studies in this review.

\section{Quality assessment}

Quality assessment scores using the MMAT ranged from $40 \%$ (two criteria met) ${ }^{3940}$ to $80 \%$ (four criteria met). ${ }^{36} 37$ The quality assessment for each study is presented in online supplemental material 3. The overall quality of the included studies was assessed as moderate to high (online supplemental material 4-table 2). Studies that focused on effectivity used mainly validated tools such as the Functional Assessment of Cancer Therapy-General ${ }^{41}$ or the Control

\begin{tabular}{|c|c|c|c|c|c|c|}
\hline $\begin{array}{l}\text { First author } \\
\text { year }\end{array}$ & Country & Study design & Study aims & Study population & Source* & $\begin{array}{l}\text { Age in years, median } \\
\text { (IQR) }\end{array}$ \\
\hline Leighl et $a l^{18}$ & $\begin{array}{l}\text { Australia and } \\
\text { Canada }\end{array}$ & RCT & $\begin{array}{l}\text { Evaluate the impact of a decision } \\
\text { aid }\end{array}$ & $\begin{array}{l}207 \text { patients with advanced, } \\
\text { incurable metastatic colorectal } \\
\text { cancer } \\
13 \text { medical oncologists }\end{array}$ & $R$ & $\begin{array}{l}\text { Patients in the control } \\
\text { group: } 62.5 \\
\text { Patients in the intervention } \\
\text { group: } 61\end{array}$ \\
\hline Hollen et a $\left.\right|^{40}$ & USA & $\begin{array}{l}\text { Prospective } \\
\text { descriptive } \\
\text { study }\end{array}$ & $\begin{array}{l}\text { Explore the feasibility and } \\
\text { acceptability of a decision aid } \\
\text { Present clinical profiles of patients } \\
\text { and their supporters dealing with } \\
\text { cancer treatment }\end{array}$ & $\begin{array}{l}80 \text { patients with solid tumours } \\
\text { ( } 22 \text { with newly diagnosed breast } \\
\text { cancer, } 19 \text { with advanced prostate } \\
\text { cancer, and } 39 \text { with advanced lung } \\
\text { cancer) } \\
80 \text { patient supporters } \\
10 \text { Healthcare professionals } \\
\text { (nurses and physicians) }\end{array}$ & $R$ & $\begin{array}{l}\text { Both patients with newly } \\
\text { diagnosed breast cancer } \\
\text { and their supporters: } 55 \\
\text { Patients with advanced } \\
\text { prostate cancer: } 72 \text {, their } \\
\text { caregivers: } 60 \\
\text { Patients with advanced lung } \\
\text { cancer: } 62 \text {, supporters: } 56\end{array}$ \\
\hline Walczak et al ${ }^{37}$ & $\begin{array}{l}\text { Australia and } \\
\text { USA }\end{array}$ & $\begin{array}{l}\text { Qualitative } \\
\text { (focus } \\
\text { group and } \\
\text { interviews) }\end{array}$ & $\begin{array}{l}\text { Explore acceptability, perceived } \\
\text { benefits and challenges of using } \\
\text { a question prompt list facilitating } \\
\text { discussion of end-of-life care } \\
\text { Determine the necessity of } \\
\text { country-specific adaptations of } \\
\text { the QPL }\end{array}$ & $\begin{array}{l}34 \text { patients with advanced, } \\
\text { incurable cancer and a life } \\
\text { expectancy }<12 \text { months ( } 15 \\
\text { Australian patients, } 19 \text { US } \\
\text { patients) } \\
13 \text { oncology and palliative care } \\
\text { health professionals ( } 7 \text { Australian } \\
\text { professionals, } 6 \text { US professionals) }\end{array}$ & $S$ & $\begin{array}{l}\text { Australian patients: } 68 \\
\text { (54-86) } \\
\text { US patients: } 58 \text { (34-75) } \\
\text { Australian healthcare } \\
\text { professionals: } 45 \text { (39-50) } \\
\text { US healthcare professionals: } \\
\text { N/A }\end{array}$ \\
\hline Yeh et $a^{\beta 8}$ & USA & $\begin{array}{l}\text { Quantitative, } \\
\text { non- } \\
\text { randomised }\end{array}$ & $\begin{array}{l}\text { Assess feasibility of a question } \\
\text { prompt list in oncology } \\
\text { consultations }\end{array}$ & $\begin{array}{l}27 \text { patients with advanced or } \\
\text { metastatic head and neck cancer } \\
\text { (stage III/IV) }\end{array}$ & $S$ & Patients: 57 (35-87) \\
\hline Walczak et al ${ }^{36}$ & Australia & Qualitative & $\begin{array}{l}\text { Explore nurse-led communication } \\
\text { support programme with question } \\
\text { prompt list that promotes end-of- } \\
\text { life discussions }\end{array}$ & $\begin{array}{l}31 \text { patients (life expectancy }<12 \\
\text { months) with advanced, incurable } \\
\text { cancer } \\
11 \text { informal caregivers }\end{array}$ & $S$ & $\begin{array}{l}\text { Patients: } 63(33-85) \\
\text { Caregivers: } 62(36-75)\end{array}$ \\
\hline Walczak et al ${ }^{\beta 5}$ & Australia & $\begin{array}{l}\mathrm{RCT} \\
\text { (parallel } \\
\text { group) }\end{array}$ & $\begin{array}{l}\text { Evaluate efficacy of a nurse- } \\
\text { facilitated communication support } \\
\text { programme for patients with } \\
\text { advanced, incurable cancer }\end{array}$ & $\begin{array}{l}110 \text { patients (life expectancy }<12 \\
\text { months) with advanced, incurable } \\
\text { cancer }\end{array}$ & $S$ & Patients 64 (33-88) \\
\hline $\begin{array}{l}\text { Henselmans } \\
\text { et } a^{\beta 9}\end{array}$ & $\begin{array}{l}\text { The } \\
\text { Netherlands }\end{array}$ & $\begin{array}{l}\text { Mixed } \\
\text { methods }\end{array}$ & $\begin{array}{l}\text { Examine patients' and relatives' } \\
\text { views on patient communication } \\
\text { aid for supporting decision } \\
\text { making. } \\
\text { Examine whether the aid has } \\
\text { adverse effects on patients' well- } \\
\text { being }\end{array}$ & $\begin{array}{l}31 \text { patients with advanced cancer } \\
\text { and life expectancy }<12 \text { months } \\
\text { (13 patients in study 1, } 18 \\
\text { patients in study 2) } \\
14 \text { relatives (study 1) } \\
6 \text { oncologists (study 2) }\end{array}$ & $E$ & $\begin{array}{l}\text { Patients study 1: } 64 \text { (35- } \\
\text { 74). Relatives 45 (18-69) } \\
\text { Patients study 2: } 62 \text { (41-75) }\end{array}$ \\
\hline
\end{tabular}

Source: $S=$ Systematic search, E=experts, R=reference lists.

$\mathrm{N} / \mathrm{A}$, not available; QPL, question prompt list; RCT, randomised controlled trial. 
Preferences Scale. ${ }^{42}$ In only one of the quantitative studies, a sample size was calculated. ${ }^{18}$

\section{Tools for supporting decisions}

Five out of seven (online supplemental material 4-table 2) studies describe QPLs as tools to support the communication about decisions on life-prolonging treatment. ${ }^{35-39}$ In two studies, stand-alone QPLs were used ${ }^{37} 38$ while in three other studies, a QPL was used as part of a support programme. ${ }^{35} 3639$ Two studies describe DAs that were used in the interaction between patients, physicians and nurses during consultations. ${ }^{18} 40$

The stand-alone QPLs consisted of a booklet ${ }^{37}$ or a single-page checklist. ${ }^{38}$ Both were tested in adults with advanced cancer with the intention of preparing them prior to consultation with their physician.

Three studies involved a QPL, in the form of a booklet, as part of a support programme. ${ }^{35} 3639$ Besides the QPL, these programmes consisted of a patient communication aid in the form of a brochure ${ }^{39}$ or a nurse-led communication support programme consisting of a face-to-face meeting, a follow-up phone call $^{36}$ or a DVD discussing advance care planning. ${ }^{35}$ The programmes were designed to increase participants' ability and motivation to discuss prognosis and end-of-life care.

The DAs ${ }^{18}{ }^{40}$ consisted of a booklet, either with accompanying narration on an audiotape or compact $\operatorname{disc}^{18}$ or for use in an interactive process with a physician and a nurse. ${ }^{40}$ The DAs were designed to improve participants' quality of decision making in interaction with physicians and nurses.

Three of the seven studies of QPLs were performed by Walczak et $a l^{35-37}$ and contained the same QPL, but elements were added in each study and different outcomes were assessed. Therefore, we included the three publications of Walczak et al as separate studies in our review.

\section{Feasibility of tools for supporting decisions}

In six studies, the feasibility of the tools (online supplemental material 4-table 2) was assessed with respect to their acceptability and usefulness. ${ }^{35-40}$ Both QPLs (either as a stand-alone QPL or as part of a multifaceted programme) and DAs were considered useful, acceptable and comprehensive by patients and family, ${ }^{37-40}$ nurses $^{40}$ and physicians. ${ }^{37} 3840$ In one study, separate versions of the QPL were developed in two Western countries to accommodate differences in population and culture. ${ }^{37}$ In one programme, QPL was explicitly used by patients in $41 \%$ of consultations. ${ }^{39}$ About two thirds of patients intended to use the QPL. ${ }^{36}$ Use of a programme with QPL and a DVD did not interrupt work processes or influence consultation length. ${ }^{35}$

\section{Effectiveness of tools for supporting decisions}

In three of the seven studies, effectiveness was evaluated for a QPL that stand alone, ${ }^{38}$ a QPL in combination with a programme and $\mathrm{DVD}^{35}$ or a $\mathrm{DA}^{18}$ (online supplemental material 4-table 2). Use of just a QPL (single intervention) significantly decreased patient anxiety as measured before and after consultation (mean anxiety scores (scale of 20-80) were 46.0 previsit and 39.6 postvisit, $\mathrm{p}=0.005) .{ }^{38}$ Patients receiving the combined QPL package (including a programme and DVD) showed greater self-efficacy in communication (knowing what questions to ask) and gave more cues for discussion during the consultation compared with patients receiving standard care. ${ }^{35}$ In the evaluation of both the QPLs and the DA, no significant differences were found in patient involvement in decision making, ${ }^{18} 3538$ patient or physician satisfaction $^{18}$ or quality of life. ${ }^{18} 35$ Use of a DA with accompanying narration increased patients' understanding of therapy and survival outcomes. ${ }^{40}$

\section{DISCUSSION}

In this review, we aimed to provide an overview of tools that support healthcare professionals and patients (and family) in communication regarding decisions on lifeprolonging treatments in hospital settings. We found seven studies reporting on the feasibility and effectiveness of tools that support communication regarding decisions on life-prolonging treatments in outpatient hospital settings. In five studies, the tool consisted of a QPL, either as a stand-alone tool or as part of a multifaceted programme. In two studies, the tool consisted of a DA for use during consultation. Both QPLs and DAs were considered feasible by both patients and healthcare professionals. Furthermore, use of a QPL by adults with advanced cancer and by healthcare professionals resulted in decreased patient anxiety and increased cues from patients for discussing end-oflife care with physicians, while use of a DA increased patients' understanding of treatments and outcomes.

The overall quality of the seven studies was appraised as moderate to high. The studies differed in methodology (design and execution) and in outcomes. Six studies evaluated the feasibility of the intervention, whereas the effectiveness of the tools in helping decide about life-prolonging treatments was only determined in three studies. The scarcity of available evidence on the effectiveness of tools is in line with other reviews, which conclude that tools are generally acceptable, however are rarely evaluated for effectiveness. ${ }^{24} 43$

The three studies that measured effectiveness provided evidence that a QPL (as a stand-alone tool or as part of a multifaceted programme) decreased patient anxiety and increased the cues given by patients for discussing the end of life, while the use of an interactive DA enhanced patients' understanding and knowledge. The decrease in anxiety was found over the course of a visit in patients with advanced cancer. 
A review regarding decision making on curative treatments suggested that use of QPL had no consistent effect on patient anxiety, although unintended effects seem unlikely. ${ }^{23}$ The latter is confirmed in our review within the specified context of end-of-life care. The three studies did not find any effect of the QPLs or DA on the process of decision making, decisional regret, patients' and physicians' satisfaction or the quality of life. This is in line with other reviews, which conclude that tools improve patients' question asking and knowledge, but did not find effects on decisional preferences or regret. ${ }^{1622234344}$

The QPLs and DAs described in the studies included in this review were developed and tested in adults with advanced cancer in outpatient hospital settings. However, decisions regarding life-prolonging treatments are also relevant for patients with other advanced diseases, such as advanced stages of chronic obstructive pulmonary disease, chronic heart failure, ${ }^{45}$ chronic kidney disease ${ }^{46}$ or liver disease. ${ }^{47}$ It is known that in adults with advanced diseases, options for starting, stopping or forgoing life-prolonging treatments are often discussed only at a late stage due to discomfort about addressing end-of-life issues and uncertainty about the timing of such discussions. ${ }^{1645} 48$ Besides, healthcare professionals are often uncertain about how to address a poor prognosis or a short life expectancy, which might result in them avoiding these topics, even though those conversations may have consequences for treatment decisions. ${ }^{16-18}$ Use of QPLs (whether as a stand-alone tool or integrated in a programme) or DAs may help patients, their family and healthcare professionals to discuss these issues in relation to decision making about life-prolonging treatments.

In three studies in our review, nurses were explicitly involved in the decision-making process. ${ }^{35} 3640$ Besides, family was explicitly mentioned in three out of seven included studies. ${ }^{36} 38$ This complies with patients' desire for nurses and family to be involved. ${ }^{44}$ The role of nurses is described elsewhere as educating patients about treatments and side effects, advocating on patients' behalf and coaching them in decision making, ${ }^{12} 154950$ and nurses are seen as valuable and influential in decision making about life-prolonging treatment. ${ }^{51-53}$

The tools in the studies all involved written material. It can therefore be expected that their feasibility might be less in populations that might also be underrepresented in the study samples, such as adult migrant groups who are not native speakers of that language or people with limited health literacy. ${ }^{54} 55$ Therefore, QPLs, DAs and other supporting tools should be adapted to and evaluated in diverse populations, including groups with different cultural backgrounds and people with limited health literacy. ${ }^{55}$

\section{Strengths and limitations of the study}

A methodological strength of this review is the search in a variety of relevant literature databases combined with consultation of international experts to identify relevant studies.

Nevertheless, we were able to include only seven studies. We do not think our selection strategies were too narrow, but see this as an indication that there is a scarcity to date of tools for supporting decisions on life-prolonging treatments in patients with advanced diseases and frail older people. Another limitation concerns the fact that the included studies had a variety of designs and outcome measures, which made it impossible to perform statistic pooling. Furthermore, one study that measured effectivity had a small sample $(n=30)$, but nevertheless did find statistical significant differences in anxiety. The results are hopeful but should be confirmed by future studies.

\section{CONCLUSION}

This systematic review reveals that the use of QPLs and DAs, as a single intervention or as part of a programme, may help in communicating about treatment options with patients, which is an important precondition for making informed decisions about life-prolonging treatment in adults with advanced cancer in hospital settings. QPLs and DAs were considered feasible by both patients and healthcare professionals. QPLs reduced patient anxiety and improved patients' cue asking, while a DA improved patients' understanding.

Further high-quality studies are needed to increase knowledge about the feasibility and effectiveness of such tools, particularly in populations with advanced diseases other than cancer, as well as in frail older people. Also, more attention has to be given to whether the use of the tools improves patient outcomes and supports patients' preferences.

\section{Author affiliations \\ ${ }^{1}$ Department of Public and Occupational Health and Amsterdam Public Health research institute, Amsterdam UMC, Vrije Universiteit Amsterdam, Amsterdam, Netherlands \\ ${ }^{2}$ Center of Expertise in Palliative Care, Amsterdam UMC, Vrije Universiteit Amsterdam, Amsterdam, The Netherlands \\ ${ }^{3}$ Health, Medical and Neuropsychology Unit, Institute of Psychology, Leiden University, Leiden, The Netherlands \\ ${ }^{4}$ Medical Library, Vrije Universiteit Amsterdam, Amsterdam, The Netherlands \\ ${ }^{5}$ Nivel, Netherlands Institute for Health Services Research, Utrecht, The Netherlands}

Twitter Maureen Thodé @MaureenThode and Irene P Jongerden@IJongerden

Contributors All authors contributed to the study concept and design, the data analysis and interpretation, reviewed the final manuscript and agree to be accountable for all aspects of the work. MT and IPJ collected and extracted the data and appraised the quality of the data. Drafts and the final version of the manuscript were prepared by MT and IPJ and edited by HRWP, LMvV, JCFK, OCD and ALF.

Funding This work was supported by the Netherlands Organisation for Health Research and Development (ZonMw) (grant number: 844001513 ). $\mathrm{LMvV}$ is supported by a Young 
Investigator Grant of the Dutch Cancer Society (grant number: 10392).

\section{Competing interests None declared.}

Patient consent for publication Not required.

Provenance and peer review Not commissioned; externally peer reviewed.

Open access This is an open access article distributed in accordance with the Creative Commons Attribution Non Commercial (CC BY-NC 4.0) license, which permits others to distribute, remix, adapt, build upon this work noncommercially, and license their derivative works on different terms, provided the original work is properly cited, appropriate credit is given, any changes made indicated, and the use is noncommercial. See: http://creativecommons.org/licenses/by-nc/4. $0 /$.

\section{ORCID iDs}

Maureen Thodé http://orcid.org/0000-0002-4584-1896

H Roeline W Pasman http://orcid.org/0000-0001-6856-2964 Liesbeth M van Vliet http://orcid.org/0000-0001-7965-5998

Olga C Damman http://orcid.org/0000-0002-4482-5042

Anneke L Francke http://orcid.org/0000-0001-7953-0693

Irene P Jongerden http://orcid.org/0000-0002-6637-7631

\section{REFERENCES}

1 Etkind SN, Bone AE, Gomes B, et al. How many people will need palliative care in 2040 ? past trends, future projections and implications for services. BMC Med 2017;15:102.

2 Pieterse AH, Stiggelbout AM, Montori VM. Shared decision making and the importance of time. JAMA 2019;322:25-6.

3 Shrestha A, Martin C, Burton M, et al. Quality of life versus length of life considerations in cancer patients: a systematic literature review. Psychooncology 2019;28:1367-80.

4 Légaré F, Witteman HO. Shared decision making: examining key elements and barriers to adoption into routine clinical practice. Health Aff 2013;32:276-84.

5 Epstein RM, Duberstein PR, Fenton JJ, et al. Effect of a patient-centered communication intervention on oncologistpatient communication, quality of life, and health care utilization in advanced cancer: the voice randomized clinical trial. JAMA Oncol 2017;3:92-100.

6 Stiggelbout AM, Pieterse AH, De Haes JCJM. Shared decision making: concepts, evidence, and practice. Patient Educ Couns 2015;98:1172-9.

7 O'Connor AM, Wennberg JE, Legare F, et al. Toward the 'tipping point': decision aids and informed patient choice. Health Aff 2007;26:716-25.

8 Elwyn G, O'Connor AM, Bennett C, et al. Assessing the quality of decision support technologies using the International patient decision aid standards instrument (IPDASi). PLoS One 2009;4:e4705.

9 O'Connor AM, Stacey D, Entwistle V, et al. Decision AIDS for people facing health treatment or screening decisions. Cochrane Database Syst Rev 2003:CD001431.

10 Barry MJ, Edgman-Levitan S. Shared decision making-pinnacle of patient-centered care. N Engl J Med 2012;366:780-1.

11 Beach MC, Sugarman J. Realizing shared decision-making in practice. JAMA 2019;322:811-2.

12 Elwyn G, Durand MA, Song J, et al. A three-talk model for shared decision making: multistage consultation process. BMJ 2017;359:j4891.

13 Shay LA, Lafata JE. Where is the evidence? A systematic review of shared decision making and patient outcomes. Med Decis Making 2015;35:114-31.

14 Joseph-Williams N, Newcombe R, Politi M, et al. Toward minimum standards for certifying patient decision AIDS: a modified Delphi consensus process. Med Decis Making 2014;34:699-710.
15 Tariman JD, Mehmeti E, Spawn N, et al. Oncology nursing and shared decision making for cancer treatment. Clin J Oncol Nurs 2016;20:560-3.

16 Bélanger E, Rodríguez C, Groleau D. Shared decision-making in palliative care: a systematic mixed studies review using narrative synthesis. Palliat Med 2011;25:242-61.

17 Graham R, Lepage C, Boitor M, et al. Acceptability and feasibility of an interprofessional end-of-life/palliative care educational intervention in the intensive care unit: a mixedmethods study. Intensive Crit Care Nurs 2018;48:75-84.

18 Leighl NB, Shepherd HL, Butow PN, et al. Supporting treatment decision making in advanced cancer: a randomized trial of a decision aid for patients with advanced colorectal cancer considering chemotherapy. J Clin Oncol 2011;29:2077-84.

19 Bolt EE, Pasman HRW, Willems D, et al. Appropriate and inappropriate care in the last phase of life: an explorative study among patients and relatives. BMC Health Serv Res 2016;16:655.

20 Bloomer M. Palliative care provision in acute and critical care settings: what are the challenges? Palliat Med 2019;33:1239-40.

21 Sepucha KR, Abhyankar P, Hoffman AS, et al. Standards for universal reporting of patient decision aid evaluation studies: the development of SUNDAE checklist. BMJ Qual Saf 2018;27:380-8.

22 Légaré F, Adekpedjou R, Stacey D, et al. Interventions for increasing the use of shared decision making by healthcare professionals. Cochrane Database Syst Rev 2018;7:CD006732.

23 Sansoni JE, Grootemaat P, Duncan C. Question prompt lists in health consultations: a review. Patient Educ Couns 2015;98:1454-64.

24 Spronk I, Burgers JS, Schellevis FG, et al. The availability and effectiveness of tools supporting shared decision making in metastatic breast cancer care: a review. BMC Palliat Care 2018;17:74.

25 Spronk I, Meijers MC, Heins MJ, et al. Availability and effectiveness of decision AIDS for supporting shared decision making in patients with advanced colorectal and lung cancer: results from a systematic review. Eur J Cancer Care 2019;28:e13079.

26 Cardona-Morrell M, Benfatti-Olivato G, Jansen J, et al. A systematic review of effectiveness of decision AIDS to assist older patients at the end of life. Patient Educ Couns 2017;100:425-35.

27 Volandes AE, Paasche-Orlow MK, Mitchell SL, et al. Randomized controlled trial of a video decision support tool for cardiopulmonary resuscitation decision making in advanced cancer. J Clin Oncol 2013;31:380-6.

28 Smith TJ, Dow LA, Virago EA, et al. A pilot trial of decision AIDS to give truthful prognostic and treatment information to chemotherapy patients with advanced cancer. J Support Oncol 2011;9:79-86.

29 Schubart JR, Green MJ, Van Scoy LJ, et al. Advanced cancer and end-of-life preferences: curative intent surgery versus noncurative intent treatment. J Palliat Med 2015;18:1015-8.

30 Shamseer L, Moher D, Clarke M, et al. Preferred reporting items for systematic review and meta-analysis protocols (PRISMA-P) 2015: elaboration and explanation. BMJ 2015;350:g7647.

31 Jeste DV, Eglit GML, Palmer BW, et al. Supported decision making in serious mental illness. Psychiatry 2018;81:28-40.

32 Ouzzani M, Hammady H, Fedorowicz Z, et al. Rayyan-a web and mobile app for systematic reviews. Syst Rev 2016;5:210.

33 Hong QN, Fàbregues S, Bartlett G, et al. The mixed methods appraisal tool (MMAT) version 2018 for information professionals and researchers. EFI 2018;34:285-91. 
34 Crowe M, Sheppard L. A review of critical appraisal tools show they lack rigor: Alternative tool structure is proposed. $J$ Clin Epidemiol 2011;64:79-89.

35 Walczak A, Butow PN, Tattersall MHN, et al. Encouraging early discussion of life expectancy and end-of-life care: a randomised controlled trial of a nurse-led communication support program for patients and caregivers. Int J Nurs Stud 2017;67:31-40.

36 Walczak A, Henselmans I, Tattersall MHN, et al. A qualitative analysis of responses to a question prompt list and prognosis and end-of-life care discussion prompts delivered in a communication support program. Psychooncology 2015;24:287-93.

37 Walczak A, Mazer B, Butow PN, et al. A question prompt list for patients with advanced cancer in the final year of life: development and cross-cultural evaluation. Palliat Med 2013;27:779-88

38 Yeh JC, Cheng MJ, Chung $\mathrm{CH}$, et al. Using a question prompt list as a communication aid in advanced cancer care. J Oncol Pract 2014;10:e137-41.

39 Henselmans I, Brugel SD, de Haes HCJM, et al. Promoting shared decision making in advanced cancer: development and piloting of a patient communication aid. Patient Educ Couns 2019;102:916-23.

40 Hollen PJ, Gralla RJ, Jones RA, et al. A theory-based decision aid for patients with cancer: results of feasibility and acceptability testing of DecisionKEYS for cancer. Support Care Cancer 2013;21:889-99.

41 Cella DF, Tulsky DS, Gray G, et al. The functional assessment of cancer therapy scale: development and validation of the general measure. J Clin Oncol 1993;11:570-9.

42 De Las Cuevas C, Peñate W. Validity of the control preferences scale in patients with emotional disorders. Patient Prefer Adherence 2016;10:2351-6.

43 de Mik SML, Stubenrouch FE, Balm R, et al. Systematic review of shared decision-making in surgery. Br J Surg 2018;105:1721-30.

44 Baik D, Cho H, Masterson Creber RM. Examining interventions designed to support shared decision making and subsequent patient outcomes in palliative care: a systematic review of the literature. Am J Hosp Palliat Care 2019;36:76-88.
45 Chen-Scarabelli C, Saravolatz L, Hirsh B, et al. Dilemmas in end-stage heart failure. J Geriatr Cardiol 2015;12:57-65.

46 Lederer S, Fischer MJ, Gordon HS, et al. A question prompt sheet for adult patients with chronic kidney disease. $B M C$ Nephrol 2016;17:155.

47 Low JTS, Davis S, Greenslade L, et al. Improving communication in outpatient consultations in people with cirrhosis: the development of a question prompt list (qpl). J Clin Gastroenterol 2020. doi:10.1097/ MCG.0000000000001347. [Epub ahead of print: 14 Apr 2020].

48 Covvey JR, Kamal KM, Gorse EE, et al. Barriers and facilitators to shared decision-making in oncology: a systematic review of the literature. Support Care Cancer 2019;27:1613-37.

49 Stacey D, Higuchi KAS, Menard P, et al. Integrating patient decision support in an undergraduate nursing curriculum: an implementation project. Int J Nurs Educ Scholarsh 2009;6:Article10.

50 Tariman JD, Szubski KL. The evolving role of the nurse during the cancer treatment decision-making process: a literature review. Clin J Oncol Nurs 2015;19:548-56.

51 Truglio-Londrigan M, Slyer JT. Shared decision-making for nursing practice: an integrative review. Open Nurs J 2018;12:1-14.

52 McCarter SP, Tariman JD, Spawn N, et al. Barriers and promoters to participation in the era of shared treatment decision-making. West J Nurs Res 2016;38:1282-97.

53 McCullough L, McKinlay E, Barthow C, et al. A model of treatment decision making when patients have advanced cancer: how do cancer treatment doctors and nurses contribute to the process? Eur J Cancer Care 2010;19:482-91.

54 Manalo MFC. End-of-life decisions about withholding or withdrawing therapy: medical, ethical, and religio-cultural considerations. Palliat Care 2013;7:PCRT.S10796-5.

55 Noordman J, van Vliet L, Kaunang M, et al. Towards appropriate information provision for and decision-making with patients with limited health literacy in hospital-based palliative care in western countries: a scoping review into available communication strategies and tools for healthcare providers. BMC Palliat Care 2019;18:37. 